\title{
A dança e seus significados na comunidade Quilombola Kalunga em Goiás/Brasil
}

\section{Dance and its meanings in the Kalunga Quilombola community in Goiás / Brazil}

\section{La danza y sus significados en la comunidad Kalunga Quilombola en Goiás / Brasil}

iD 9 Rosirene Campêlo dos Santos

Universidade Estadual de Goiás, Goiânia, Goiás, Brasil.

E-mail: rosi.dance14@gmail.com

iD (9) Reigler Siqueira Pedroza

Universidade Estadual de Goiás, Goiânia, Goiás, Brasil. e-mail: reigler@hotmail.com

iD (9) Dulce Maria Filgueira de Almeida Universidade de Brasília, Brasília, Distrito Federal, Brasil. E-mail: dulce.filgueira@gmail.com

Resumo: Este estudo busca analisar os processos de transição que vêm ocorrendo na vida cotidiana da comunidade Kalunga em relação à percepção das danças entre as gerações de idosos e jovens. Foi realizada uma pesquisa etnográfica utilizando entrevistas e observação direta na comunidade. A interpretação ocorreu com base em autores que discutem o tema no campo das ciências sociais no diálogo com a educação física. Como conclusão, podemos afirmar que os corpos se entrelaçam nas festas e danças e promovem diálogos de dança estabelecidos entre gerações. O sistema ritual, constituído por festas e danças, revela os sentidos e significados das danças como uma estratégia de resistência cultural, permitindo a reconstrução do passado e a ressignificação do presente desse grupo social.

Palavras-chave: Dança. Festa. Grupos Étnicos. 


\begin{abstract}
This study seeks to analyze the transition processes that have been occurring in the daily life of the Kalunga community in relation to the perception of dances among the elderly and young generations. An ethnographic research was carried out using interviews and direct observation in the community. The interpretation occurred based on authors who discuss the topic in the field of social sciences in the dialogue with physical education. As a conclusion, we can say that the bodies are intertwined in parties and dances and promote dance dialogs established between generations. The ritual system reveals the senses and meanings of the dances as a strategy of cultural resistance, allowing the reconstruction of the past and the re-signification of the present of this social group.
\end{abstract}

Keywords: Dancing. Party. Ethnic Groups.

Resumen: Este estudio busca analizar los procesos de transición que se vienen dando en la vida diaria de la comunidad Kalunga en relación a la percepción de los bailes entre las generaciones mayores y jóvenes. Se realizó una investigación etnográfica mediante entrevistas y observación directa en la comunidad. La interpretación se dio a partir de autores que discuten el tema en el campo de las ciencias sociales en el diálogo con la educación física. Como conclusión, podemos decir que los cuerpos se entrelazan en fiestas y bailes y promueven los diálogos de danza establecidos entre generaciones. El sistema ritual revela los sentidos y significados de las danzas como estrategia de resistencia cultural, permitiendo la reconstrucción del pasado y la resignificación del presente.

Palabras-clave: Baile. Partido. Grupos Étnicos.

Submetido em: 25-08-2020

Aceito em: 26-04-2021 


\title{
Introdução
}

\begin{abstract}
Para se iniciar no modus vivendi das comunidades negras e em seu estar no mundo, há que conhecer-Ihes as festas, observar o conteúdo musical entoado nos rituais, os gestos dos corpos dançantes, as vestes, instrumentos utilizados, a religiosidade, os costumes. Precisa-se fazer análise diacrônica dos elementos de sua cultura, como se comportam e transpõem o tempo, e.g. a superstição religiosa africana ao catolicismo e como isto se deu no pretérito; detectar as re-significações. Em análise sincrônica verificar-se-á como as festas se organizam os constitutivos, a relação cenário/ atores/regras e símbolos movem as recorrências (MOURA, 2004, p. 94).
\end{abstract}

Sinônimo de regozijo, divertimento, distração, por vezes até de desordem, as festas atravessam distintos contextos sociais e culturais. Sociologicamente, constituem-se em uma forma de propiciar e reforçar laços de sociabilidade entre indivíduos em suas relações cotidianas. São uma forma de celebração, portanto. Por meio da festa, os atores sociais constroem, significam e ressignificam seus papéis sociais, podendo ser de natureza profana, sagrada ou híbrida (na qual há uma ambivalência entre esses dois elementos), isto é, quando envolve tanto aspectos sagrados quanto profanos, a depender do tipo de ritual a ela associado. Para nós, em sua conformação, a festa ocorre por meio de ritos, constituindo um processo ritual marcado por práticas corporais revestidas de técnicas do corpo, que são tradicionais e eficazes (MAUSS, 2003).

No que diz respeito à especificidade das festas religiosas cristãs, Petruski (2011) aponta para a existência de duas categorias básicas. Primeiramente, as solenidades coletivas que são privilégio de fato da Igreja, por dependerem da condução eclesiástica. Segundo, as comemorações que, embora sejam regidas por uma moral e fé cristã, são realizadas nas ruas, praças e até em propriedades particulares, por pessoas e grupos que não estão necessariamente e/ou diretamente relacionadas com o poder da Igreja. 
A dança e seus significados na comunidade Quilombola Kalunga em Goiás/Brasil Rosirene Campêlo dos Santos • Reigler Siqueira Pedroza • Dulce Maria Filgueira de Almeida

Ao considerar a força com que o catolicismo age no calendário e vida social brasileira, podemos encontrar nas culturas populares muitos exemplos que se encontram situados na segunda categoria apontada por Petruski (2011), tais como o Congado, as Romarias, Folias de Reis, Santos e do Divino Espírito Santo. Acontecimentos que, entre outras instâncias, forjam o catolicismo popular brasileiro e que são construídos conforme suas singulares, consoante a um processo ritual, com base em práticas corporais que se performatizam em romarias, cantorias, procissões, rezas e danças.

No contexto do povo Kalunga, pesquisadores como Silva Junior (2008) e Siqueira (2006) apontam a existência de festas que fazem referência a São João, Nossa Senhora das Neves, Nossa Senhora d'Abadia, Nossa Senhora do Livramento, Nossa Senhora Aparecida, São Sebastião, São Gonçalo, Santos Reis e Divino Espírito. Na abordagem de Siqueira (2006), essas festas podem ser percebidas do ponto de vista da performance como algo agenciado por atores sociais que vivem o encontro como forma de renovar alianças e reciprocidades, de fortalecer a fé, de fazer pedidos de bênçãos e de namorar, rememorar, dançar e brincar.

Consoante a essa compreensão, o presente artigo tem por objetivo interpretar o significado da dança em uma festa religiosa, denominada de "festa de São Sebastião", em uma comunidade de afro descentes, reconhecidos legalmente como quilombolas, da ramificação Kalunga ${ }^{1}$. Essa população habita na zona rural, dentro dos limites territoriais do município de Teresina de Goiás, no estado de Goiás, situado na região Centro-Oeste do Brasil.

A dança e a festa de São Sebastião serão aqui interpretadas com base em informações obtidas em campo, em que se procurou realizar um exercício etnográfico. Portanto, as observações de campo constituem parte substantiva da interpretação dada à descrição densa. Para a construção da análise, autores das Ciências Sociais e do campo da Educação Física serão tratados de modo a propiciar a melhor apropriação do fenômeno que se investi-

1 Nome atribuído a descendentes de escravos fugidos, que habitam regiões de antigos quilombos na região central do Brasil, no caso em tela, no Estado de Goiás (cf. notas de campo, 2011). 
A dança e seus significados na comunidade Quilombola Kalunga em Goiás/Brasil

Rosirene Campêlo dos Santos • Reigler Siqueira Pedroza • Dulce Maria Filgueira de Almeida

ga, a saber: o significado da festa religiosa de São Sebastião na Comunidade Quilombola kalunga.

Com a preocupação de que a curiosidade e o interesse antropológico não nos façam incorrer no risco, sempre eminente, da exotização, mas, sim, na potência de compreender a pluralidade das identidades negras brasileiras, lança-se o olhar para os Kalunga na busca de interpretar o processo pelo qual diferentes contornos do agir, no contexto da festa religiosa, se constituem em marcas de suas identidades que se constroem a partir de distintos papéis sociais.

\section{Metodologia}

Pesquisar é, sobretudo, apropriar-se de diferentes conceitos e metodologias, em um processo devidamente delineado quanto ao foco de investigação, para conhecer o que ainda não se conhece ou conhecer, diferentemente, um objeto, fato ou fenômeno social que outros pesquisaram, mas dentro de outro paradigma ou enfoque metodológico. Nesse caso, a pesquisa é de natureza qualitativa, já que, para estudar os processos rituais nas festas e, consequentemente, as danças da comunidade quilombola, fez-se necessário analisar as relações que perpassam os sentidos e os significados atribuídos pelos atores sociais nessa manifestação.

Dessa maneira, para a concepção da pesquisa, lançou-se mão dos seguintes artefatos: diário de campo, observações, entrevistas, conversas informais, fotografias e vídeos. Esses recursos ofereceram as condições necessárias à aproximação com a realidade social da comunidade Kalunga, como também uma interpretação da relação sentido-significado, tal qual Cardoso de Oliveira (1998) propõe em seu texto - Ver, ouvir e escrever. Nele, o autor reconhece que o trabalho do pesquisador - no seu caso, do antropólogo - envolve a interpretação do sentido em significado, posto que as falas, os gestos, enfim, a dança entre os Kalunga produz e recria uma educação do corpo, que se reveste de aspectos simbólicos. 
O delineamento da pesquisa foi etnográfico, tendo como lócus a Comunidade Quilombola Kalunga, em especial os grupamentos situados no município de Teresina de Goiás, no estado de Goiás, que se autonomeiam Ema, Ribeirão e Limoeiro, visto que o território da comunidade se estende até os municípios de Cavalcante e Monte Alegre. Referente às técnicas utilizadas na investigação, por se tratar de uma pesquisa etnográfica, a observação direta foi a principal forma de obtenção de dados. Para a análise, foi realizada descrição densa das informações, com base nos registros do diário de campo.

\section{Resultados e discussão}

Para compreender o cenário das danças na comunidade Kalunga, se faz necessária a compreensão do processo ritual que envolve toda a festa, pois somente é possível analisar seus sentidos e significados imersos no contexto das festas. Nesse sentido, iremos enfatizar a folia de São Sebastião, uma importante festa do povo Kalunga.

A Folia de São Sebastião é marcada por rituais específicos de abertura e encerramento, que têm início e término em uma data específica e local próprio. No caso da Folia de São Sebastião, que acompanhamos junto à comunidade quilombola Kalunga de Teresina de Goiás, a festa se iniciou no dia 15 de outubro e terminou no dia 20 daquele mês.

Na composição do grupo de foliões que comandam a Folia de São Sebastião, somente aos homens é permitida a participação, sendo esta composta de dez homens que saem a cavalo para realizar o giro da Folia, visitando as casas adjacentes. Em cada casa, reza-se e canta com a família; geralmente, a família oferece alguns donativos para a festa ou alguma contribuição em dinheiro, também são oferecidos café e bolo aos foliões. A chegada dos foliões nas casas durante o giro é vista com muita satisfação e alegria por todos e trata-se de um motivo de agradecimento ao santo devoto. 
São Sebastião é um santo de devoção da comunidade Kalunga, mas também é conhecido em todo Brasil, sendo padroeiro de várias paróquias e comunidades. Em sua imagem, a figura do santo aparece amarrado a um tronco, tendo sido atingido ao longo de todo o seu corpo por flechas. Historicamente, São Sebastião é reconhecido por sua bravura e pela incansável proteção aos cristãos perseguidos. Sua sina para se tornar santo ocorreu quando ele passa os postulados do cristianismo, mesmo tendo recebido promessas de honrarias e riquezas caso renegasse a Jesus Cristo, o que não ocorreu. Então, foi morto por um grupo de soldados, que o amarraram a uma árvore e desfiaram contra ele flechadas. No entanto, apesar de todo o sacrifício, São Sebastião foi encontrado vivo, tornando-se o santo protetor contra a fome, a perseguição e a peste.

O povo Kalunga acredita que a realização da folia é uma forma de agradecer e de receber as bênçãos para os momentos difíceis vividos por aquele grupo social. Eles acreditam também que o santo Ihes concederá graças, bênçãos, curas e interseção junto a Deus e garantirá fartura à mesa. Desse modo, a festa de São Sebastião tem como significado precípuo os agradecimentos e os pedidos de proteção, situando-se, nesse âmbito, no universo do sagrado, ainda que carregue consigo a natureza do regozijo da folia, o que a investiria de qualidades profanatórias.

Vale ressaltar que o entendimento de sagrado passa por formulações limítrofes entre as ciências das religiões e a sociologia. Autores como Durkheim, Hubert e Mauss, Roger Callois e Mircea Eliade tratam da experiência do sagrado em órbitas distintas. Em relação ao sagrado, Durkheim (2003, p. 342) enfatiza que "o respeito que temos por um ser sagrado transmite-se, pois, a tudo o que tem contato com esse ser, a tudo o que se parece com ele e faz lembrá-lo".

Assim, conforme Durkheim (2003, p. 24): 
As coisas sagradas são aquelas que as proibições protegem e isolam; as coisas profanas, aquelas a que se aplicam essas proibições protegem e que devem permanecer à distancia das primeiras. As crenças religiosas são representações que exprimem a natureza das coisas sagradas e as relações que elas mantêm, seja entre si, seja com as coisas profanas. Enfim os ritos são regras de conduta que prescrevem como o homem deve comportar-se com as coisas sagradas.

Não obstante, assim como para Hubert e Mauss (2003), para Durkheim, as relações com o sagrado são estabelecidas por meio do interdito, no entanto, para esses dois últimos autores, o sagrado, além de se reportar ao interdito, é mediado pelo sacrifício, avançando, portanto, esses dois autores em relação ao pensamento de Durkheim.

A esse respeito, Hertz (1970, p. 106), em um texto clássico que trata da polaridade religiosa, com base na preeminência da mão direita sobre a esquerda, ressalta, entre outros aspectos, que: “O universo inteiro está dividido em duas esferas contrastantes: coisas, seres e poderes atraem e se repelem mutuamente, incluem ou se excluem mutuamente, dependendo do fato de gravitarem em direção a um ou outro dos polos". O fio condutor do pensamento do autor é o de que a polaridade social é um reflexo, uma espécie de consequência da polaridade religiosa. Sendo assim, todas as oposições exibidas pela natureza partem desse dualismo fundamental.

Nesses termos, podemos operar com a compreensão de que o sagrado é tudo aquilo que se reveste por um interdito, porém é dotado de uma força ativa que o contrapõe ao profano. Contudo, apesar de possuir uma relação de subordinação com o sagrado, o profano em troca se constitui por uma potência que dessacraliza, sendo, por assim dizer, profanadora (BASTIDE, 1975). Há entre sagrado e profano uma profunda dialética no sentido de alimentação e retroalimentação, tal qual a necessidade do alimento para o ser humano. 
Especificamente nessa retroalimentação entre sagrado e profano, a festa de São Sebastião entre os Kalunga apresenta algumas peculiaridades que merecem destaque. O primeiro aspecto do evidente é que a festa começa a ser preparada muito antes do dia 20 de outubro. O começo de sua preparação se dá desde o momento em que alguém da comunidade se prontifica a promover a folia, seja por uma graça alcançada, como, por exemplo, a cura de uma doença.

A folia será aqui entendida como um ritual, que, no dizer de Peirano (2003, p.40), é:

(...) é uma forma de ação, sobretudo maleável e criativa que, com conteúdos diversos, é utilizada para várias finalidades. O ritual - agora definido etnograficamente, isto é, em termos nativos tornou-se um fenômeno interessante para análise justamente porque, no longo processo de reflexão sobre suas características intrínsecas, reconheceu-se que ele tem o poder de ampliar, iluminar e realçar uma série de idéias e valores que, de outra forma, seriam difíceis de discernir.

Como um ritual que ocorre em processo, cujo fim é ampliar, iluminar e reforçar ideias e valores da comunidade, um pouco antes do dia da festa propriamente dita, a casa que receberá os foliões e os festeiros é ornamentada com balões coloridos, coloca-se som mecânico, bandeirinhas etc. À sua frente, uma cruz é posta e adornada com balões e velas e, além da cruz, um arco também recebe os mesmos adereços. Há, simultaneamente, a preparação do interior da casa. Nela, é colocado um pequeno altar, que contém imagens dos santos devotos e, notadamente, a imagem do santo padroeiro - São Sebastião. Toda essa ornamentação e os preparativos da festa são de responsabilidade daqueles que receberão a folia (os foliões) em pouso, com maior ressonância ao papel social ocupado pelas mulheres da comunidade.

Os foliões chegam à casa após uma longa caminhada a cavalo. Logo à frente está o Alferes, que é o guardião da bandeira/estan- 
darte da folia. Porto (1982, p. 19) afirma que a função do Alferes é "(...) carregar respeitosamente a Bandeira, a apresentando-a ao chefe da casa onde a folia acaba de chegar, e receber os donativos oferecidos pela família". Cabe também ao Alferes ser o guardião dos ritos da folia, determinando quando e de que forma as ações performáticas ocorrerão, além de resguardar o cumprimento das regras pelos foliões.

Antes de entrarem, iniciam uma espécie de vigília, com cantos e rezas, por mais ou menos uma hora, performance esta denominada de "entrega da folia". Nesse momento do processo ritual, apenas os homens - foliões - participam, abrindo-se uma exceção para a "encarregada" da folia, que, nesse ano, foi Dona Irene. Os demais participantes da festa acompanhavam atentos a realização da entrega da folia, apreciando e valorando a realização do rito pelos foliões. Enquanto isso, as mulheres da comunidade estavam na cozinha realizando os últimos preparativos para a festa, que incluíam comida e bebida para serem servidas durante toda a noite.

É importante destacar nessa passagem a clara distinção de papéis sociais e de gênero. Na folia, homens e mulheres ocupam espaços diferenciados, o que nos faz recordar do estabelecimento do interdito às mulheres que, por exemplo, em determinadas culturas, são proibidas de tocar no alimento em certos períodos, sobretudo, quando menstruadas. Parafraseando Porto (1982, p. 50), "de modo geral, não se admite a presença de mulher, numa folia. Abrem-se exceções para o caso de promessas, quando então, a mulher é admitida como acompanhante, sem direito a cantar, nem tocar instrumento". Nesse caso, parece evidenciar-se uma relação de ambivalência entre sagrado e profano, em que são estabelecidas relações de atração e repúdio. No caso em tela, o fato de apenas os homens cavalgarem e serem reconhecidos na comunidade como os foliões ajuda a legitimar a evidência do papel social que ocupam.

No decorrer da festa, foi possível observar a divisão das atividades, envolvimento e participação entre homens e mulheres, ficando claro o papel social a ser desenvolvido por cada um nos 
diferentes momentos e rituais que compõem a festa. A participação das mulheres na festa de São Sebastião pode ser observada nos seguintes momentos: o primeiro deles é no preparo dos alimentos para o jantar, que é servido depois da chegada dos foliões. No decorrer do dia, especificamente ao entardecer, as mulheres da comunidade se reúnem na cozinha para o preparo do jantar, ficando a dona da casa responsável pelo direcionamento das tarefas a serem feitas. Como é uma festa de grande porte e que tem participação de pessoas das comunidades vizinhas, faz-se bastante comida. Geralmente, improvisam vários fogões a lenha, para agilizar o preparo dos diversos alimentos. Nessa oportunidade, as mulheres conversam, contam piadas e relembram outros momentos festivos, sendo um espaço de sociabilidade.

Na continuidade do processo ritual, após a chegada e a vigília, os foliões se aproximam da casa cantando, param em frente da cruz e rezam. Nesse momento, soltam-se vários fogos de artifício, o que ajuda a iluminar a noite escura e anuncia um momento de culminância. Os foliões seguem em direção à casa e ao altar, e o rito determina que todos passem por debaixo do arco enfeitado. A partir do instante em que os foliões atravessam o arco, toda a comunidade se aproxima e passa a acompanhar a procissão dos foliões. Os foliões seguem sempre à frente ditando o ritmo dos atos performáticos.

A entrada na casa também se constitui como um lugar importante do processo ritual. Naquela ocasião, por ser a casa de encerramento da folia, a esta se atribui um aspecto de sagrado, sobretudo porque na frente da sala está disposto o altar cuidadosamente preparado para a folia. Sendo assim, todos os foliões, ao entrarem, fazem reverência ao altar e iniciam os cantos e benditos de agradecimentos. Dona Irene, a dona da folia, e sua neta, que recebeu a graça, ajoelham-se em frente ao altar e permanecem até o fim dos agradecimentos. Notou-se na circunstância que a reverência era feita com o sinal da cruz, utilizando-se da mão direita, similar à tradição católica. 
Mais uma vez, Hertz (1970) nos ajuda a entender o momento de reverenciar com a mão direita, assim como todo aquele sinal de agradecimento por algo recebido, dá-se com o movimento de estender a mão direita, ou mesmo o fato de todos os foliões retirarem da cabeça o chapéu, movimento também realizado pela mão direita, como símbolo de respeito ao ambiente que se adentra e ao espaço sagrado que foi constituído como cenário na casa de Dona Irene. Segundo ele, como na devoção, o homem busca se comunicar com os poderes sagrados, as técnicas que ele irá utilizar para conseguir essa comunicação devem ser as mais apropriadas possíveis, assim, apenas a mão direita é a que está apta para realizar esse movimento, já que, sendo considerada sagrada, facilita a comunicação com o divino. Por essa razão, as oferendas sagradas são ofertadas com a mão direita; é à direita que concede a bênção do "Deus te abençoe meu filho(a)"; todos os movimentos do padre no âmbito do ritual da missa católica são realizados com a mão direita, enfim, em diferentes culturas, (...) o movimento e posição contrários, em circunstâncias similares, seriam sacrilégios" (HERTZ, 1970, p. 116).

Depois desse momento de agradecimento e de devoção, inicia-se o jantar. Primeiramente, os foliões são convidados a se servirem, logo em seguida toda a comunidade é convidada. O jantar termina com a reza do bendito da mesa. Nessa reza, os foliões agradecem pelos alimentos que ali foram servidos e deixam no centro da mesa apenas um garfo sobre uma colher em forma de $X$. Ao consultarmos sobre a representação simbólica do garfo e da colher, nos foi dito que esse cruzamento representa a origem do mundo, o momento em que Deus criou o homem e a mulher. Nos diz com propriedade Hertz:

Como pode o corpo do homem, o microcosmo, escapar da lei da polaridade que governa tudo? A sociedade e todo o universo têm um lado que é sagrado, nobre e precioso e outro que é profano e comum: um lado masculino, forte e ativo, e outro feminino, fraco e passivo; ou, em outras palavras, um lado direito e um lado esquerdo (1970, p. 108). 
Vale ainda mencionar que todos os cantos foram acompanhados com a movimentação dos foliões em torno da mesa e mais uma vez somente a Dona Irene pôde participar junto com os foliões. Por ser a encarregada da folia, gozou da autorização para participar de atos performáticos da folia, visto que esse espaço tende a se restringir ao universo dos homens. Verifica-se que, em todos os momentos da festa, os rituais são seriamente respeitados pelos atores sociais, inclusive pelas pessoas de outras comunidades que vieram como convidadas.

Sobrevindo esse momento, na sala em frente ao altar, as muIheres começam a se reunir e iniciam a reza do terço, com cantos, benditos e ladainhas a São Sebastião e a outros Santos de devoção da comunidade. Nessa ocasião, são poucos os homens presentes. Alguns estão lá fora conversando e os outros, como Seu Antônio, estão preparando o mastro para ser levantado. Ao final das orações, a comunidade sai em procissão em direção ao lugar onde o mastro será erguido. Ao lado desse lugar é preparada uma fogueira.

Seu Antônio e uma senhora vão à frente da procissão levando a bandeira/estandarte com a imagem do santo homenageado. Rezando e cantando, a procissão gira três vezes ao redor do mastro antes de ser erguido, as demais pessoas da comunidade acompanham com uma vela artesanal feita de cera da abelha iratim. Esse momento é mágico e fascinante de se ver. Todos param, e Seu Antônio, juntamente com alguns homens, coloca a bandeira/ estandarte na ponta do mastro, que é erguido. Soltam-se muitos fogos de artifício. Esse momento de fincada do mastro corresponde ao ápice da festa, aqui se estabelece um momento de liminaridade entre o sagrado e o profano, visto que após o mastro erguido começam as danças profanas e cessam as rezas e cantorias religiosas.

Segundo Moura (2004, p.95): 
As práticas religiosas, inseparáveis das festas, revelam a dinâmica cultural das comunidades negras rurais. O ritualismo aparece como modo das comunidades apresentarem a si sua cíclica organização social. Pelas constantes que se repetem, percebe-se a estrutura que articula celebrações a festividades. Quanto mais incidentes, mais perceptivelmente semelhantes.

Pode-se dizer que os rituais presentes na Folia de São Sebastião possuem "teias de significados", que, segundo Geertz (2008), ajudam a revelar a cultura do grupo social por meio das práticas tradicionais e dos costumes.

Além disso, pode-se interpretar a forma de conduzir a bandeira/estandarte por parte do Alferes como uma prática corporal que se reveste por um conjunto de técnicas. Nas palavras de Mauss: “Não há técnica e tampouco transmissão se não há tradição. É nisso que o homem se distingue sobretudo dos animais: pela transmissão de suas técnicas e muito provavelmente por sua transmissão oral" (2003, p. 407).

Na sequência da colocação do mastro, a primeira prática corporal que dá ensejo ao momento não religioso é a dança sussa. A sussa é uma dança típica da comunidade Kalunga, em que apenas as mulheres ocupam o papel de centralidade. Elas dançam no meio da roda, enquanto os homens cantam e tocam os instrumentos. Aqui, nota-se, mais uma vez, a ambivalência do processo ritual, pois, no momento que se inicia a dança, considerado o momento profano da folia, as mulheres passam a ocupar a cena, sendo delas a performance. Parafraseando Almeida e Suassuna (2010, p.59), as histórias e as relações sociais que constituem o grupo são revividas durante as danças e, enquanto dançam, as pessoas tomam seus lugares na sociedade, revelando as identidades dos corpos e mecanismos de resistência ou aceitação de novos padrões culturais. A sussa, por seu turno, representa a manutenção da tradição cultural do grupo dos Kalunga de Teresina de Goiás; por meio dela, a memória desse grupo social é mantida e transmitida como uma técnica corporal tradicional e eficaz (MAUSS, 2003). 
Outro aspecto a ser destacado é que durante a sussa se oferta aos presentes bebida alcóolica, no caso, o vinho, finalizando o rito de levantamento do mastro. A partir desse instante, a música mecânica surge e todos os presentes se interagem, socializam e começam a dançar. Na sequência da sussa, dançada apenas pelas mulheres mais velhas da comunidade, todos os demais começam a dançar o forró. Daí, os processos de interação e as redes de sociabilidade se materializam de diferentes formas, tanto conhecidos quanto desconhecidos dançam entre si, mulheres dançam entre si, jovens e velhos, enfim; trata-se do momento de reforçar os laços comunitários e de socialização.

Ao observar a participação das mulheres na festa de São Sebastião, conclui-se que esta não se difere da maioria dos papéis socialmente atribuídos às mulheres que vivem em comunidades tradicionais ou na zona rural. De acordo com as pesquisas de Chaves (2003), Porto (1982) e Gonçalves (2010), além das observações realizadas da participação das mulheres na folia de São Sebastião, podemos inferir que as próprias mulheres "já aceitaram" sua condição, que é de ficar quase "invisível", mas presente ao mesmo tempo. Porém, se de um lado, é função dos homens desempenharem os principais papéis no decorrer da folia, seria impossível a sua realização sem o envolvimento das mulheres e de seu trabalho nos bastidores, pois são elas que, além de prepararem os alimentos, decoram, ornamentam e constroem os cenários que servirão como local para receber a folia. Desse modo, a organização do altar, a disposição das imagens dos Santos e a própria reza do terço, as ladainhas e os benditos são atribuições das mulheres, daí não se pode falar que elas ocupem um papel social secundário, porém o seu papel se constitui como algo distinto do dos homens.

Por seu turno, os jovens estão presentes na folia de modo significativo, isto é, eles participam no momento do festejo final, contudo a maioria deles não se envolve com o processo ritual em si, apenas observa e, no final, participa do momento de socialização por meio da dança. Nesse ponto, a dança apresenta um valor sim- 
bólico relevante, pois ela é responsável pelo momento de unidade do grupo. Todos participam da dança, independentemente da idade, sexo ou habilidade para dançar. Ela representa, portanto, o instante da integração social, por meio do congraçamento e, de uma forma ou de outra, contribui para a manutenção dos costumes e das tradições no âmbito da folia de São Sebastião.

\section{Conclusão}

De modo geral, evidenciou-se que a festa de São Sebastião apresenta dois momentos ambivalentes. O primeiro, em que dele participam, sobretudo, os homens, corresponde à ocasião dedicada ao sagrado, à religiosidade, aos cantos, à reza do terço, às ladainhas, aos benditos, à procissão em volta do mastro, à devoção, ao momento de louvar e agradecer pelas bênçãos e graças recebidas, como também de se renovar os pedidos. O segundo momento constitui-se pela dedicação ao profano, em que começa a dança, passando a festa a ser um acontecimento social, de regozijo, de divertimento, de ludicidade, de troca e interação social.

Portanto, a folia de São Sebastião atende, como outras manifestações da cultura corporal humana, a uma ambivalência, uma hibridez, pois, para além dos momentos de descontração e divertimento, é também o local da religiosidade, da devoção, do agradecimento e não somente da graça recebida, mas da colheita bem-sucedida, da chuva que caiu na medida certa, da saúde para plantar e colher. Nessa relação de ambivalência, as danças apresentam um significado fundamental, pois elas, tanto a sussa quanto o forró, representam o processo de socialização, que encerra o processo ritual da folia, após a fincada do mastro. A dança representa o momento da transgressão consentida, que pode ser compreendido como o instante em que o sagrado se torna ambivalente, isto é, torna-se profano. Enfim, a festa traz em si uma conformação ambivalente entre sagrado e profano.

Por fim, os ritos que envolvem o processo ritual da Folia de São Sebastião possuem uma multiplicidade de signos e significa- 
dos e, por meio deles, é possível compor um mosaico da vida cotidiana da comunidade Kalunga, de Teresina de Goiás, entendendo, sobretudo, a divisão de papéis entre homens e mulheres ou mesmo a forma como a comunidade se relaciona com a ambivalência entre o sagrado e o profano no contexto da folia de São Sebastião.

\title{
Referências
}

\begin{abstract}
ALMEIDA, Arthur José Medeiros de; SUSSUNA, Dulce Filgueira de Almeida. Práticas corporais, sentidos e significado: uma análise dos jogos dos povos indígenas. Revista Movimento. Porto Alegre, v. 16, n. 04, p. 53-71, 2010.

BASTIDE, Roger. Le sacré sauvage. Paris: Payot, 1975.
\end{abstract}

CARDOSO DE OLIVEIRA, R. 0 trabalho do antropólogo. Brasília/ São Paulo: Paralelo 15. Ed. Unesp, 1998.

CAILLOIS, R. Los juegos y los hombres: la máscara y el vértigo. México: Fondo de Cultura Econômica, 1994.

CHAVES, W. N. D. Na Jornada de Santos Reis: uma etnografia da Folia de Reis do Mestre Tachico. Rio de Janeiro: UFRJ / MN / PPGAS, 2003.

DURKHEIM, E. As formas elementares da vida religiosa. São Paulo: Martins Fontes, 2003.

ELIADE, Mircea. O sagrado e o profano. São Paulo: Martins Fontes, 1992.

GONÇALVES, Maria Célia da Silva. As Folias de Reis de João Pinheiro: Performance e Identidades Sertanejas no Noroeste Mineiro. 2010. 00f. Tese (Doutorado em Sociologia) Universidade de Brasília, Brasília, 2010.

GEERTZ, Clifford. A interpretação das culturas. Rio de Janeiro: LTC - Livros Técnicos e Científicos Editora S.A.,2008. 
A dança e seus significados na comunidade Quilombola Kalunga em Goiás/Brasil

Rosirene Campêlo dos Santos • Reigler Siqueira Pedroza • Dulce Maria Filgueira de Almeida

HERTZ, Robert. A preeminência da mão direita: um estudo sobre a polaridade religiosa. Religião e Sociedade, Rio de Janeiro:

Tempo e Presença, 1970.

HUBERT, H; MAUSS, M. Sobre o sacrifício. São Paulo: Cosac Naify, 2003. 174p. MAUSS, Marcell. Sociologia e Antropologia. São Paulo: Cosac \& Naify, 2003.

MOURA, Gloria. Festas Quilombolas. In: Patrimônio imaterial, performance cultural e (re) tradicionalização. Brasília: ICS- UNB, 2004. PEIRANO, Mariza. Rituais ontem e hoje. Rio de Janeiro: Jorge Zahar. Ed., 2003.

PETRUSKI, Maura Regina. As Festas de Sant'Ana de outrora em Ponta Grossa. Revista Mneme, Natal, v. 12, n. 30, 2011.

PORTO, Guilherme. As folias de reis no sul de Minas. Rio de Janeiro: MEC/SEC/FUNARTE, Instituto Nacional do Folclore, 1982.

SIQUEIRA, Thaís Teixeira. Do tempo da sussa ao tempo do forró, música, festa e memória entre os kalunga de Teresina de Goiás. 2006. 129f. Dissertação (Mestrado em Antropologia Social) - Universidade de Brasília, Brasília, 2006.

SILVA JR., Augusto Rodrigues. Festejo quilombola: o Kalunga, o divino, o verso. In: IV ENECULT - Encontro de Estudos Multidisciplinares em Cultura, Faculdade de Comunicação/ UFBa, Salvador, 2008.

SILVA JR., Augusto Rodrigues. Vozes e versos na festa quilombola dos kalunga. Revista África e Africanidades, Rio de Janeiro, Ano I, n. 1, maio. 2008.

\section{Publisher}

Universidade Federal de Goiás. Faculdade de Educação Física e Dança. Publicação no Portal de Periódicos UFG. As ideias expressadas neste artigo são de responsabilidade de seus autores, não representando, necessariamente, a opinião dos editores ou da universidade. 